\title{
METROPOLIZACIÓN VERSUS CIUDADES INTERMEDIAS. LA INCOMPATIBILIDAD DEL AUGE DE LAS CIUDADES INTERMEDIAS EN LA FASE ACTUAL DE LA URBANIZACIÓN DE LA POBLACIÓN COLOMBIANA.
}

\section{ÓSCAR A. ALFONSO-ROA*}

Recibido: 16 de noviembre de 2017

Aprobado: 15 de diciembre de 2017

Artículo de Reflexión

\footnotetext{
* Doctor en Planeamiento Urbano y Regional. Docente investigador Universidad Externado de Colombia, Bogotá, Colombia. E-mail: oscar.alfonso@uexternado.edu.co. @ ORCID: 0000-0003-0781-0658. Google Scholar
} 


\title{
Resumen
}

La noción de la ciudad intermedia más frecuentemente utilizada es el tamaño poblacional y su crecimiento intertemporal, y de manera complementaria su funcionalidad. En este trabajo se sostiene que la naturaleza de ese fenómeno es diferente cuando se detecta en un ámbito metropolitano que cuando ocurre de manera relativamente aislada. Una ciudad intermedia es aquella que ocupa un lugar intermedio en la jerarquía urbana de un país. Es por ello que cuando el proceso de metropolización de la población no ha alcanzado su madurez, es improbable que ocurra una bifurcación de la urbanización hacia una ciudad intermedia o hacia un conjunto de estas.

Palabras clave: urbanización, ciudades, áreas urbanas, población urbana.

\section{METROPOLISATION VERSUS MID- SIZED CITIES.THE INCOMPATIBILITY OF THE RISE OF MID-SIZED CITIES IN THE CURRENT PHASE OF URBANIZATION OF THE COLOMBIAN POPULATION.}

\begin{abstract}
The notion of mid-sized city most frequently used is the population size and its intertemporal growth and, in a complementary way, its functionality. In this paper it is argued that the nature of this phenomenon is different when detected in a metropolitan environment than when it occurs in a relatively isolated manner. A mid-sized city is one that occupies an intermediate position in the urban hierarchy of a country. That is why when the process of metropolization of the population has not reached maturity, it is unlikely that there will be a bifurcation of urbanization towards a mid-sized city or towards a set of these.
\end{abstract}

Key words: urbanization, cities, urban areas, urban population.

I n la fase de la metropolización de la población es poco probable un auge del crecimiento de las ciudades intermedias. Lasfuerzascentrípetas que suscitan el crecimiento metropolitano no se desvanecen sino entrada una etapa como la de la desurbanización 
donde el drecrecimiento absoluto de la población en esas zonas es coetáneo a su manifestación en otras zonas, seguramente las ciudades intermedias. Medidas como el crecimiento poblacional absoluto y la funcionalidad de las ciudades, son pertinentes para verificar si en efecto está ocurriendo una bifurcación del crecimiento urbano con el ímpetu requerido para alterar las jerarquías del sistema de ciudades.

En el VII Foro Urbano Mundial el auge de las ciudades intermedias en Colombia fue uno de los temas centrales (Semana, 2014), allí se divulgó una línea de interpretación que ha sido seguida por estudios recientes como los del Banco Interamericano de Desarrollo - BID - (Torres y Caicedo, 2015). A fin de discutir este tipo de aproximaciones se realiza un balance crítico de los análisis acerca de dicho auge en el mundo, para luego proponer una línea teórica de abordaje — path dependence de la urbanizacióncon la que se procura explicar la incompatibilidad de la simultaneidad de dos movimientos como la metropolización de la población y el auge de las ciudades intermedias. En la tercera parte se esbozan algunos indicadores para establecer la estructura del sistema urbano y su dinámica para, posteriormente, presentar los análisis relativos al caso colombiano. En las reflexiones finales se sintetizan de manera crítica las cuestiones más acuciantes de esta reflexión.

\section{El apogeo de las ciudades intermedias y el olvido de su declive poblacional}

¿Se encuentra el planeta en una fase de bifurcación del crecimiento poblacional urbano? Desde finales del siglo XX, y desde organizaciones de diversa índole, se han difundido trabajos cuyos resultados redundan en la premisa de un auge de las ciudades intermedias.

La CEPAL (1998), con el apoyo del Ministerio de Asuntos Exteriores de Italia, promovió un estudio con cuyos resultados se pretendía "facilitar el cambio y la adopción de nuevos roles por parte de los gobiernos locales en las ciudades intermedias" (p. 11); definiéndolas como aquellas ciudades que contaban con más de 50000 pero menos de un millón de habitantes, sobrepasadas en jerarquía por las ciudades grandes - de 1 a 4 millonesy las metrópolis - más de 4 millones-y así preconizar una tendencia a la contracción en la participación de las metrópolis en los sistemas urbanos caracterizada por la pérdida de dinamismo en la generación de puestos de trabajo y en la creación de nuevas oportunidades para la inserción de la población en el mundo moderno. 
Por su parte, y desde finales de la década de los 90, la Unión Internacional de Arquitectos ha desarrollado una postura acerca de la "práctica del urbanismo en ciudades intermedias" (Bellet y Llop, 2004, p. 34) partiendo de la premisa del olvido académico para con estas; en donde, según ellos, reside la mayor parte de la población del planeta. En desarrollo de su postura el tamaño poblacional es insuficiente para definir la ciudad intermedia, criterio que debería complementarse con los de funcionalidad e interacción; además después de identificadas es posible verificar sus ventajas en relación con las grandes aglomeraciones en materia de equilibrio y sostenibilidad ambiental, gobernabilidad y empoderamiento de sus residentes, así como menos competitividad y menor diversidad social.

Más recientemente, desde la organización Ciudades y Gobiernos Locales Unidos —CGLU- (2015), se afirmó que "más de la mitad de la población urbana en el mundo habita en ciudades intermedias". Bajo la orientación académica de Llop, el documento reafirma tanto el escepticismo sobre el tamaño poblacional para definir la ciudad intermedia - actitud que extienden a los "criterios únicamente cuantitativos" - como el potencial clarificador de los criterios de funcionalidad, interacción y de capacidad para operar en red; y precisan cuatro pautas a seguir: la población flotante en relación con la población residente, las competencias administrativas y el presupuesto y las conectividades externas e internas; es decir, criterios que son susceptibles de cuantificar.

El BID se ocupó nuevamente del estudio de las ciudades intermedias en Colombia, seleccionando a 57 cuya población oscila en el rango entre 100000 a un millón; con el fin de responder a la cuestión de “¿cuáles serían las ciudades intermedias y autónomas mayores a 100.000 habitantes de mayor potencial de crecimiento integral que a futuro asumirán funciones como centros alternos y de relevo del proceso de desarrollo en el país?" (Torres y Caicedo, 2015, p. 8). Se midió el crecimiento poblacional, los promedios del índice de desempeño integral, del índice de desempeño fiscal y de los impuestos municipales per cápita y se identificaron las ciudades con el criterio de que ellas serían las que tuviesen un valor de todos los indicadores superior al del promedio de las seleccionadas. Los resultados se analizan con base en una tipología del Departamento Nacional de Planeación -DNP- (2014), dando lugar a una clasificación en tres subgrupos siendo el primero el que reúne a las de mejor desempeño. Salvo dos de las nueve que los conforman, y a las que se les atribuye un comportamiento relativamente autónomo, las restantes pertenecen a las grandes aglomeraciones urbanas del país. 
En otros ámbitos se argumenta acerca del carácter duradero de este fenómeno. En la invitación del Lincoln Institute of Land Policy —LILP(2017), a postularse a uno de sus cursos de perfeccionamiento sobre la gestión de los fenómenos urbanos contemporáneos en América Latina, se plantea que "hoy las ciudades de tamaño intermedio encabezan el crecimiento poblacional urbano creando enormes retos para las ciudades emergentes". Otro tanto suscribe el BID a partir de la premisa de que "hoy, en las geografías en desarrollo, la urbanización está siendo empujada por una red de ciudades intermedias pero de crecimiento acelerado" (Terraza, Rubio y Vera, 2016, p. 26). Estos enfoques son compartidos por estudios como el del Cities Alliance, en donde se plantea que:

el mayor crecimiento absoluto de la población se dará en las ciudades secundarias de entre uno y cinco millones de habitantes. Se espera que estas ciudades aumenten su población en 460 millones entre 2010 y 2025, mientras que las megaciudades de todo el mundo incrementarán su población en 270 millones. (Roberts, 2015, p. 43)

Son escasos los seguimientos que se hacen a este tipo de predicciones, pero su credibilidad no es el objeto de este trabajo sino los órdenes de magnitud que son tan amplios como para contribuir a reafirmar la idea de un auge en el crecimiento de las ciudades intermedias.

Son escasos y, en general, poco referenciad os en los medios académicos los trabajos que plantean argumentos en contra. La desindustrialización que ha afectado a los territorios norteamericanos pertenecientes al "Anillo del Óxido" se ha asociado a la desurbanización de metrópolis como Detroit, pero también a la de ciudades industriales intermedias de la misma zona como Búfalo, San Luis y Cleveland (Pallagst, 2008). En Francia el fenómeno ha sido captado en ciudades industriales intermedias como Saint-Éttiene, Le Havre, Thionville y Le Creusot (Béal et al., 2017). Otros estudios enfatizan en sus determinantes tales como el envejecimiento de la población, el funcionamiento anómalo del mercado de trabajo y los desbalances en la distribución de género como determinantes de su "declive demográfico" que afecta al menos a una tercera parte de las áreas urbanas funcionales (Cauchi-Duval, Cornuau and Rudolph, 2017). Hay evidencias de que este fenómeno también afecta a reconocidas aglomeraciones manufactureras como Leipzig en Alemania y Liverpool en Inglaterra. Hackworth (2017) se aparta de los discursos que consideran el declive urbano como algo natural asociado exclusivamente a fenómenos económicos como la desindustrialización cuando el conflicto social expreso en modalidades como el racismo y la intolerancia los han antecedido propiciando el abandono 
de vecindarios por sus antiguos residentes, generalmente afroamericanos. Por su parte, Dormois y Fol (2017) se ocupan de la necesidad de intervenir sobre el fenómeno de la desurbanización y la relativa ausencia de políticas al respecto.

\section{La dependencia histórica de la urbanización del presente y la histéresis metropolitana}

La estructura de los sistemas urbanos contemporáneos y de sus jerarquías es indisociable de su trayectoria histórica (histéresis). Siguiendo a Mahoney (2000), es posible explicar este fenómeno a partir de tres razones: (i) la existencia de mecanismos de autorefuerzo, que propulsan a las aglomeraciones contemporáneas a erigirse como las metrópolis del presente y del futuro venidero; (ii) a la constatación de la existencia de efectos de retroalimentación cuya función es la de reafirmar de manera secular la trayectoria del proceso de urbanización y (iii) que habiendo existido oportunidades para introducir bifurcaciones al sistema urbano ellas no fueron aprovechadas, sin embargo la posibilidad de choques externos como la globalización e internos como el conflicto interno armado hoy por hoy es virtualmente imposible la modificación espontánea de los procesos de ocupación del territorio.

Una explicación acerca de la complejización o simplificación de los sistemas socioecológicos es pertinente para comprender la existencia o la ausencia de mecanismos de autorefuerzo de la urbanización. Los ecosistemas simples tienden a ser inestables debido a que no se producen las compensaciones indispensables para el sostenimiento de la vida (Hoenigsberg, 1977). Ciertos ambientes han sido simplificados por el hombre como en el caso de los afectados por el uso de plaguicidas que, en su infructuoso combate a la irrupción súbita de depredadores de las cosechas, han ocasionado que antes que desaparecer experimenten cierta evolución orgánica que los torna más resistentes a los pesticidas; aunque, simultáneamente, han afectado negativamente hasta causar la extinción de algunas cadenas vegetales. Pero también ha producido sistemas complejos y las ciudades son el mejor ejemplo de ello. Las diferencias en el tamaño de las ciudades se explican en buena medida por la confluencia en espacio y tiempo de cierta variedad debienes y servicios. En ausencia de tal variedad los ambientes se tornan monótonos, estado donde la escasez de oportunidades de elección constriñe la adecuada y oportuna satisfacción de algunas de las necesidades de la población demandante. A la base de esta explicación de la diversidad como sinónimo de complejización se encuentran fenómenos como el de la innovación de bienes y de procesos que tienen como lugar 
privilegiado los mercados densos y que, como en el caso de la teoría del ciclo internacional de vida del producto nuevo (Vernon, 1973), sitúan las etapas de lanzamiento y perfeccionamiento en las ciudades donde es factible amortizar los costos de la investigación y detectar las fallas del bien o servicio para alcanzar la fase de estandarización. Desde esta perspectiva la fuente de autorefuerzo de las metrópolis es el incremento en la variedad de bienes y servicios que allí circulan, lo que facilita la existencia y la periódica renovación de las compensaciones en las canastas de consumo.

Por su parte los procesos de retroalimentación son de dos signos - positivos o negativos-, pero en ningún caso neutrales. La economía marshalliana (Fujita, Krugman y Venables, 2000) plantea la interacción en lugar y tiempo de fuerzas centrípetas y de fuerzas centrífugas a fin de explicar el devenir de las aglomeraciones. En el primer caso, los eslabonamientos productivos, la densidad de los mercados y la existencia de externalidades positivas no pecuniarias harían parte de las retroalimentaciones positivas; mientras que la inmovilidad de factores, el precio elevado y creciente del suelo urbano y otras deseconomías puras como la congestión, la polución y la inseguridad física operan en sentido contrario. El saldo neto favorable a la retroalimentación centrípeta es una idea que induce a pensar, tal cual es planteada por este enfoque, que este es generado de forma endógena. Sin embargo las grandes aglomeraciones lo son porque en su proceso de crecimiento también han producido mecanismos mercantiles de complementariedad cuya existencia es inmanente a un mundo donde las autarquías fueron superadas por sistemas abiertos de los que deviene la manutención y el crecimiento de la riqueza social. Los sistemas urbanos hacen parte de este tipo de sistemas y tienden a gravitar, cada vez con mayor intensidad, sobre las metrópolis que establecen el mayor número de complementariedades (Isard, 1960; Chasco, 2000); es decir de la interacción con otros mercados localizados comenzando por los del interior del país.

La tercera cuestión es tratada como la oclusión y se refiere al momento donde es imposible el retorno a una situación previa o, de manera alternativa, la posibilidad de una bifurcación que es obstruida (Martínez, 2016); reafirmándose la trayectoria que seguía el fenómeno en curso, en este caso, la urbanización de la población. La población jamás se ha encontrado en estado de reposo y las metrópolis que se han formado acogen una variedad de funciones sobre las que tienden a gravitar la dinámica del conjunto del sistema urbano. $\mathrm{Si}$, como complemento, el desarrollo de los medios y los modos de transporte de carga y de pasajeros se van ajustando al ideal euclidiano, los campos gravitatorios de los centros urbanos tienden a ampliarse a condición de que esas ventajas que contribuyen a quebrar la "tiranía de la distancia" (Prager et Thisse, 2010) se localicen en su campo de 
influencia. Eficaces intentos para modificar la trayectoria de la urbanización han sido de orden institucional tal como la modificación del sistema de empadronamiento en la China conocido como hukou y también atribuibles a una deliberada política de industrialización. Esta eficacia se constata en la inflexión de la trayectoria histórica de la tasa de urbanización como resultado de la eliminación gradual de los mecanismos que promovían la oclusión de la urbanización (Zhuoyong, 2008).

Como resultado del acumulado histórico de las diferencias de diversidad, complementariedad y oclusión, el fenómeno resultante es la histéresis metropolitana que conviene a un estado perenne de la urbanización de la población donde las grandes aglomeraciones —las metrópolis - tienden a ser cada vez más grandes; es decir a aportar una porción estable y creciente de la población al sistema urbano, así se intente transgredir la oclusión con políticas desconcentradoras. Y en presencia de histéresis metropolitana, las bifurcaciones del sistema urbano hacia las ciudades intermedias es al menos poco probable.

\section{El crecimiento de las ciudades intermedias y la metropolización}

Hay diferencias entre la ciudad intermedia y la metrópoli. Una metrópoli no es meramente la "ciudad-centro" (Lefèvre, 2014) sino el conjunto urbano donde se identifican relaciones funcionales dinámicas que dan lugar a fenómenos como la suburbanización residencial, el declive de las actividades rurales en sus áreas de influencia inmediata y el incremento persistente en los desplazamientos cotidianos, entre los más acuciantes, y cuyo resultado es la conformación de unidades espaciales de mayor tamaño. Algunos estudios como el del BID aluden a "ciudades intermedias" tanto a las que hacen parte de procesos de metropolización como a algunas que no comparten esta dinámica. En este trabajo se sostiene, desde esta noción de metrópoli, que la naturaleza de las mismas es sustancialmente diferente y que por lo tanto son ciudades intermedias, indistintamente de su tamaño poblacional, las que ocupan un lugar intermedio de la jerarquía urbana.

Las tasas de crecimiento poblacional son una medida necesaria, pero no suficiente, para establecer el auge de las ciudades intermedias. Barro y Sala-i-Martin $(1991,1992)$ postulan la regla de la convergencia consistente en que las economías crecen más rápidamente cuanto menor es su nivel de partida o - en el mismo sentido- que el ingreso de los habitantes de los países más pobres será — en algún momento- similar al de los países ricos. Si se han de emplear las tasas de crecimiento habría que precisar que, para 
que exista dicho auge, la de cierta ciudad intermedia es tan superior a la de la metrópoli que el crecimiento absoluto de población también lo es y que debe ser de tal magnitud como para alterar las jerarquías poblacionales.

Es frecuente encontrar análisis que promueven la idea del auge poblacional y funcional de ciudades intermedias que, en la práctica, sostienen fuertes interacciones con núcleos metropolitanos y con municipios adyacentes de la misma área de influencia; es decir que son jurisdicciones metropolizadas. Esto significa, entre otras cosas, que una porción de su crecimiento poblacional se debe al saldo migratorio positivo que experimentan con el núcleo metropolitano. Son cambios de lugar de residencia principal que generalmente toman la forma de suburbanización de capas medias y altas en el área de influencia inmediata por motivos autosegregativos; llegando en cierta etapa a manifestarse en lugares más lejanos por causa de la instalación de segundas residencias por motivos de ocio y que, con el avance del ciclo de vida de sus propietarios, terminan siendo su residencia principal. Cuando a estas jurisdicciones que son parte de una dinámica de conjunto como es la metropolización se les trata por fuera de tal contexto, se les desnaturaliza de su contexto territorial dominante.

Un auge en el crecimiento de las ciudades intermedias debería verificarse por otras medidas con las que sea posible captar un cambio sustancial en la estructura del sistema urbano y que, de llegar a constatarse, abriría en efecto un prolífico programa de investigación orientado a desvendar la naturaleza de los cambios ocurridos y que condujeron al sistema a bifurcase; y a apartarse de su trayectoria dependiente de su pasado. Un primer conjunto de medidas son las que resultan del uso de los indicadores primaciales. En la visión histórico-comparativa del desarrollo económico y la primacía urbana, Cuervo (2004) indica que las relaciones que la ciudad primada establece con el resto del sistema urbano se verifican en los cambios en su participación en la población, el empleo, la generación de riqueza, la distribución del poder y las innovaciones. Las medidas empleadas son:

índice de población total

$$
I P T=\frac{P_{1}}{P T}
$$

índice de cuatro ciudades

$$
I C C=\frac{P_{1}}{\sum_{i=2}^{4} P_{i}}
$$

coeficiente de intensidad cronológica

$$
C I C=\frac{\Delta I P T}{t}
$$


$P_{1}$ es la población de la primera ciudad y $t$ es el tiempo transcurrido entre dos medidas del IPT. Varias conclusiones son de interés para esta reflexión como, por ejemplo, el carácter diacrónico y sincrónico del fenómeno; sin embargo la idea de que en una visión de muy largo plazo "el crecimiento de la primacía arriba a un punto de saturación" (Cuervo, 2004, p. 83) es de mayor relevancia, pues indica que precisamente desde tal punto ocurre una inflexión en la trayectoria dependiente del sistema urbano en cuestión debido probablemente a una crisis económica o a un severo proceso de desindustrialización, estancamiento de la primacía que es coetáneo al avance poblacional de otras aglomeraciones, probablemente de las ciudades intermedias. A partir de ese punto sobrevendría la desconcentración del sistema urbano y la consecuente relajación de la importancia de la ciudad primada.

En el estudio del sistema urbano en China, Zhuoyong (2008) empleó tres indicadores primaciales a fin de analizar las disparidades espaciales de la distribución de las ciudades por su tamaño en las provincias de este país:

índice de dos ciudades

índice de cuatro ciudades

índice de once ciudades

$$
S_{2}=\frac{P_{1}}{P_{2}}
$$

$$
S_{4}=\frac{P_{1}}{\sum_{i=2}^{4} P_{i}}
$$

$$
S_{11}=\frac{2 P_{1}}{\sum_{i=2}^{11} P_{i}}
$$

Donde el subíndice en $P_{i}$ indica el rango de la metrópoli, correspondiéndole el primero a la más grande, y $P_{1}$ es el tamaño de la población de la ciudad primada. Cuando $S_{2}>2, S_{4}>1$ y $S_{11}>1$ el sistema urbano asiste a un proceso de concentración, cuando los indicadores principales son iguales a los umbrales el sistema se encuentra en equilibrio y cuando son menores ello es sintomático de un proceso de desconcentración y por lo tanto pérdida del grado de primacía. La dispersión de la población en la provincia, en este último caso, es sintomática de distribución más equilibrada en el territorio tal como ocurre en varias provincias entre las que Shandong es un caso emblemático por estar a la cabeza de la tercera megalópolis más populosa de la China; en el otro extremo, el sistema urbano de Shanghái y Jiangsu es muy concentrado. 
La trayectoria dependiente que da lugar a los sistemas urbanos, a sus jerarquías, escalas y formas de aglomeración, no está gravada en piedra. Es plausible pensar en el auge de las ciudades intermedias, aunque es pertinente recalcar la idea de la constatación de la existencia de cambios significativos en los aportes al crecimiento poblacional dentro del sistema urbano los cuales están -en principio- asociados positivamente a los ciclos del desarrollo urbano. En cualquier sistema urbano es posible detectar simultáneamente los cuatro ciclos del desarrollo urbano (Piperno et al., 2014). La concentración del crecimiento poblacional y de las actividades económicas en los núcleos urbanos caracteriza al ciclo de la urbanización y lo distingue del subsiguiente que es el de la metropolización que comienza a detectarse con los fenómenos de autosegregación de hogares de capas de ingresos medios y altos que dan origen a procesos de suburbanización residencial; fenómeno que es coetáneo a la segregación involuntaria o forzada de los hogares de bajos ingresos en dirección de jurisdicciones aledañas que, generalmente, se concretan en conurbaciones difusas de expansión popular; en este sentido ocurren los procesos de localización y relocalización de la actividad económica en dirección a las jurisdicciones localizadas en el área de influencia inmediata de los núcleos metropolitanos, movimiento a partir del cual la interacción cotidiana - movimientos pendulares- y la interacción estructural—cambios de residencia del núcleo metropolitano hacia los municipios en proceso de metropolización — se acentúa. Los saldos migratorios son positivos para los municipios metropolizados y, de manera consecuente, son de signo contrario para los núcleos metropolitanos. Por esta razón, además de su dinámica demográfica autónoma —crecimiento vegetativo, principalmente-, las tasas de crecimiento poblacional se incrementan en los municipios metropolizados pudiendo superar la de los núcleos metropolitanos. Una fase más avanzada de este fenómeno ocurre por la extensión de esa interacción más allá del área de influencia inmediata y que se caracteriza por la selectividad de ciertos espacios por familias pudientes que demandan la segunda residencia y que, llegada cierta etapa avanzada del ciclo de vida de los jefes de hogar, se convierte en la residencia principal: en este contexto, es lo que se denomina metropolización lejana.

Por su parte el ciclo de la desurbanización que en épocas pasadas tuvo como determinantes a los conflictos bélicos y a los llamados "desastres naturales" es una fase de declive poblacional que con cada vez más frecuencia está determinada, por una parte, por debacles económicas y políticas; y, por otra, por la incursión de la Nación a una nueva transición demográfica. El balance de esta etapa puede tener varios signos puesto que las pérdidas socioeconómicas derivadas de la dispersión de la actividad económica previamente localizada en los conjuntos urbanos implica, con 
sus matices, la disminución de la concentración que es captable a través de la disminución de los índices de primacía. Dependiendo de la magnitud de la desurbanización las políticas y los nuevos diseños institucionales pueden revertir el ciclo para conducirlo a uno nuevo, el de la reurbanización donde el crecimiento del núcleo y del resto del conjunto urbano se acompaña de una modificación del orden residencial y socioeconómico precedente. Estos ciclos tienen impactos profundos en diferentes planos comenzando por el de la fiscalidad de las jurisdicciones involucradas en cada uno de ellos (Piperno et al., 2014).

La metropolización de la población es la fase actual de la urbanización de la población que, en la mayoría de los casos, precede a la conformación de megalópolis concentradas o desconcentradas. Los indicadores primaciales se reducen cuando se consideran las zonas metropolitanas como unidades espaciales, así no cuenten aún con un gobierno de esa escala. Esta aparente contradicción surgida de la manera como un fenómeno de expansión urbana que da lugar a la conformación de una unidad socioespacial de mayor escala - la metrópoli (Lèfebvre, 2014) - encarna una moderación de la primacía de la ciudad primada; ocurriendo precisamente por la redistribución del crecimiento poblacional en los municipios metropolizados, dialéctica de la urbanización que refuerza la idea de que las ciudades intermedias no se deben buscar en las zonas metropolitanas.

¿Qué ocurre en el resto del sistema urbano? Los ciclos del desarrollo urbano son susceptibles de asimilar para analizar lo que ocurre en las zonas rurales; aunque - antes de ello y siendo consecuentes con las tres nociones de la trayectoria dependiente - se propone una taxonomía donde la urbanización adopta tres formas dependientes de su persistencia, relanzamiento o lanzamiento, mientras que la desurbanización también se observa en perspectiva histórica y a partir de tal observación se precisa si es un fenómeno persistente o reciente. Estas mismas categorías se emplean para clasificar las zonas rurales de las mismas jurisdicciones en las que, además, es posible detectar unas cuantas que no tienen cabecera municipal — sin urbanización - y otras que teniéndola no disponen sino de ella, pues no tienen una zona rural — sin ruralización-. El resultado que se obtiene es un conjunto de cuatro sistemas que, empleando las nociones de complejización y simplificación de la teoría ecológica, se denominan como: sistemas robustos, urbanos endebles, rurales endebles y frágiles. En razón a que en cada uno de ellos se detecta al menos tres tipos de ciclo, quedan conformados por nueve categorías en las que se agrupan subsistemas socioecológicos diferenciados. 
El sistema robusto lo componen las jurisdicciones donde el crecimiento poblacional urbano y rural es simultáneo, destacándose el subsistema $R_{1}$ como el más dinámico y estable en el tiempo (tabla 1). En el sistema urbano endeble están las jurisdicciones donde la población urbana crece, pero la rural no; indicio de que las zonas rurales existentes se han copado por la cabecera o, en su defecto, se han simplificado al punto de no contar con las compensaciones necesarias para producir un hábitat rural estable. El sistema opuesto es el rural endeble donde la población urbana decrece y la rural crece, de manera que no existe en proximidad inmediata una aglomeración que complemente las dinámicas rurales. Por último, en un sistema frágil tanto la población urbana como la rural de la jurisdicción decrecen como resultado de una simplificación coetánea de ambos hábitats. Dentro de este grupo aparece $F_{9}$ que es el subsistema virgen, sin poblar, incluido para completar la matriz con el caso extremo que precede a la formación de una nueva jurisdicción por la vía del establecimiento de algún caserío o centro poblado. El ciclo de suburbanización no aparece de manera explícita debido a que está presente en cualquiera de los 30 subsistemas con algún grado de ruralización de la población.

Tabla 1. Identificación de sistemas y subsistemas no metropolitanos a partir de los ciclos del desarrollo en el contexto de la trayectoria dependiente

\begin{tabular}{lllllll}
\hline Ciclos & $\begin{array}{l}\text { Ruralización } \\
\text { persistente }\end{array}$ & Reruralización & $\begin{array}{l}\text { Ruralización } \\
\text { reciente }\end{array}$ & $\begin{array}{l}\text { Desruralización } \\
\text { persistente }\end{array}$ & $\begin{array}{l}\text { Desruralización } \\
\text { reciente }\end{array}$ & $\begin{array}{l}\text { Sin } \\
\text { ruralización }\end{array}$ \\
\hline $\begin{array}{l}\text { Urbanización } \\
\text { persistente }\end{array}$ & $\mathrm{R}_{1}$ & $\mathrm{R}_{2}$ & $\mathrm{R}_{3}$ & $\mathrm{UE}_{1}$ & $\mathrm{UE}_{2}$ & $\mathrm{UE}_{3}$ \\
\hline Reurbanización & $\mathrm{R}_{4}$ & $\mathrm{R}_{5}$ & $\mathrm{R}_{6}$ & $\mathrm{UE}_{4}$ & $\mathrm{UE}_{5}$ & $\mathrm{UE}_{6}$ \\
\hline $\begin{array}{l}\text { Urbanización } \\
\text { reciente }\end{array}$ & $\mathrm{R}_{7}$ & $\mathrm{R}_{8}$ & $\mathrm{R}_{9}$ & $\mathrm{UE}_{7}$ & $\mathrm{UE}_{8}$ & $\mathrm{UE}_{9}$ \\
\hline $\begin{array}{l}\text { Desurbanización } \\
\text { persistente }\end{array}$ & $\mathrm{RE}_{1}$ & $\mathrm{RE}_{2}$ & $\mathrm{RE}_{3}$ & $\mathrm{~F}_{1}$ & $\mathrm{~F}_{2}$ & $\mathrm{~F}_{3}$ \\
\hline $\begin{array}{l}\text { Desurbanización } \\
\text { reciente }\end{array}$ & $\mathrm{RE}_{4}$ & $\mathrm{RE}_{5}$ & $\mathrm{RE}_{6}$ & $\mathrm{~F}_{4}$ & $\mathrm{~F}_{5}$ & $\mathrm{~F}_{6}$ \\
\hline Sin urbanización & $\mathrm{RE}_{7}$ & $\mathrm{RE}_{8}$ & $\mathrm{RE}_{9}$ & $\mathrm{~F}_{7}$ & $\mathrm{~F}_{8}$ & $\mathrm{~F}_{9}$ \\
\hline
\end{tabular}

Fuente: elaboración propia por parte del autor.

El énfasis que se ha colocado hasta el momento sobre las medidas poblacionales puede ser objeto de variadas críticas como, por ejemplo, la de pasar por alto la dimensión funcional de las ciudades. Sin embargo no es posible la comprensión de los cambios en el sistema urbano sin el análisis de lo ocurrido con esta dimensión del desarrollo, la más potente 
para indicar la trayectoria dependiente de la urbanización y la existencia o no de bifurcaciones como la del auge de las ciudades intermedias. La concentración o desconcentración de funciones en las ciudades es un complemento analítico indispensable para inferir la consistencia y veracidad de los resultados obtenidos, para ello es posible obtener deducciones de utilidad analítica con el empleo de los indicadores primaciales.

Una alternativa para superar ese posible sesgo es emplear medidas estadísticas de distancia a través de procedimientos de estandarización y ponderar con algún criterio teórico las variables que dan cuenta de la funcionalidad de las ciudades. A manera de ejemplo, supóngase dos ámbitos funcionales de las ciudades con variables explicativas normalizadas con cuyo cálculo es posible establecer las distancias del tamaño funcional en lo económico (INE) y lo político (INP), resultados con los que se procede a construir una medida de funcionalidad: el índice sintético del tamaño funcional (ISTF). Tratándose de una estadística que captura las diferencias de grado o distantes entre tales variables y asumiendo que no existe sustituibilidad entre ellas; es decir que no es sensato pensar que en las ciudades se sustituye más economía por menos gobierno o cualquier otro tipo de permuta de tal naturaleza; en la ecuación (7) se asigna la misma ponderación a los índices normalizados de cada ámbito.

$$
I S T F=\left(\frac{I N E+I N P}{2}\right)
$$

El ISTF es sintético por cuanto en el cálculo de su antecedente más próximo -el índice de tamaño funcional- (Fresneda et al., 1998) se empleó un conjunto más amplio de ámbitos funcionales explicados a través de variables seleccionadas con criterio discriminante; esto, con actividades que no tuviesen presencia en todas las jurisdicciones municipales del país.

Un aspecto que no se debe perder de vista en el cálculo e interpretación de los resultados es que la heterogeneidad estructural del territorio es considerable. Esta heterogeneidad ha dado lugar a procesos de equiparación estadística tal como el empleo de las tasas por 100000 habitantes en las defunciones, procedimiento con el que se amplifica el fenómeno en las jurisdicciones con un tamaño poblacional inferior a ese umbral. ¿Este procedimiento debe ser empleado en todos los casos que involucren jurisdicciones de diferente tamaño? En Europa el uso de la nomenclatura de las unidades territoriales estadísticas permite los análisis a tres niveles: $\mathrm{NUTS}_{1}$, que subdivide a la zona en 98 regiones; $\mathrm{NUTS}_{2^{\prime}}$ en 276 y NUTS $_{3^{\prime}}$ en 1342. Análisis regionales como el de la convergencia de 
Dall'Erba y Le Gallo (2005) utilizan NUTS 2 . Barro y Sala-i-Martin (1991) hicieron algo equivalente en Estados Unidos a escala de los 50 Estados, en donde hay uno asociado más la capital. En Canadá el estudio de la convergencia regional de Coulombe y Lee (1998) comparó regiones tan disímiles como Ontario, Saskatchewan y la Isla del Príncipe Eduardo. En el otro extremo, en Singapur, no hay subdivisiones territoriales. En ningún caso se han efectuado este tipo de equiparaciones, y la existencia de convergencia regional se estimó con independencia del tamaño de las jurisdicciones.

\section{El sistema urbano colombiano, trayectoria dependiente y evidencias de cambios}

La aceleración del proceso de urbanización colombiana iniciada hacia mediados del siglo pasado es un fenómeno asincrónico con el desarrollo signado por profundos desequilibrios territoriales (Alfonso, 2014). La ciudad primada en la jerarquía urbana colombiana —Bogotá- alcanzó su primer millón de habitantes hacia 1957, cifra que Buenos Aires detentaba medio siglo atrás. A pesar de ese relativo rezago, la aceleración del crecimiento poblacional sobrevino desde entonces y no cesa; lo que implica que la primacía poblacional bogotana galopa sobre el país en urbanización desde entonces y, por lo visto, por algo más de un siglo. Hacia mediados del siglo XX la tasa de crecimiento de la población en Bogotá osciló alrededor del $7 \%$, hoy lo hace alrededor del 1,8\% y a mediados del presente siglo se proyecta que lo haga al 0,5\% ¿Y? Esta historia puede ser reproducida con sus matices para los casos de Medellín, Cali o Barranquilla. Que la tasa de crecimiento poblacional de las metrópolis decrezca o se ralentice no es noticia. Y si no lo es ¿qué puede llegar a serlo? Por ejemplo: se prevé que la tasa de Medellín se torne negativa después de 2040, lo que acarreará que esta jamás alcanzará los tres millones de habitantes. Interesan las velocidades del crecimiento poblacional urbano absoluto, por lo que es pertinente normalizarlo al millón de habitantes. Alcanzar el primer millón de habitantes fue algo extremamente dispendioso para las metrópolis colombianas (tabla 2); pero, además, ha sido un logro asincrónico por lo diferido en el tiempo y por el lapso - en años - transcurrido desde la fundación de cada jurisdicción.

El resultado del impulso inicial fue muy eficaz en Barranquilla, que es la metrópoli que alcanzó más rápidamente el primer millón de habitantes; aunque, en cambio, es a la que le tomará más tiempo alcanzar el segundo millón. Cali, que había superado efímeramente a Medellín hacia mediados de la década de los 90, lo hará de manera sostenida desde 2031. En 2041 
Bogotá alcanzará los 10 millones de habitantes y será precisamente Cali la que 13 años después conquiste un millón adicional, es decir, en 2054. En general, el lapso de adición del millón de habitantes ha sido y será considerablemente más veloz en Bogotá que en cualquier otra metrópoli del país; resultado que deriva necesariamente en el crecimiento sostenido de la primacía poblacional bogotana.

Tabla 2. Lapso de tiempo requerido (años) para la adición de un millón de habitantes en cuatro metrópolis colombianas

\begin{tabular}{|c|c|c|c|c|c|c|c|c|c|c|c|}
\hline \multirow[t]{2}{*}{ Ciudad } & \multirow[t]{2}{*}{ Tiempo } & \multicolumn{10}{|c|}{ Millones de habitantes } \\
\hline & & 1 & 2 & 3 & 4 & 5 & 6 & 7 & 8 & 9 & 10 \\
\hline \multirow[t]{2}{*}{ Bogotá } & Año & 1957 & 1967 & 1975 & 1983 & 1989 & 1998 & 2007 & 2017 & 2027 & 2041 \\
\hline & Lapso & 419 & 10 & 8 & 8 & 6 & 9 & 9 & 10 & 10 & 14 \\
\hline \multirow[t]{2}{*}{ Medellín } & Año & 1970 & 1998 & & & & & & & & \\
\hline & Lapso & 354 & 28 & & & & & & & & \\
\hline \multirow[t]{2}{*}{ Cali } & Año & 1974 & 2001 & 2054 & & & & & & & \\
\hline & Lapso & 438 & 27 & 53 & & & & & & & \\
\hline \multirow[t]{2}{*}{ Barranquilla } & Año & 1980 & 2192 & & & & & & & & \\
\hline & Lapso & 167 & 212 & & & & & & & & \\
\hline
\end{tabular}

Fuente: cálculos con base en estadísticas censales del DANE hasta el 2005 y proyecciones al 2020, y proyecciones de la Misión de Ciudades —DNP_ desde el 2021

La persistencia de la primacía poblacional de Bogotá en el sistema urbano colombiano es evidente y continuará creciendo en las próximas décadas, al decir de los resultados de los indicadores primaciales de la figura 1. El índice de primacía urbana total -IPUT—alcanzó su máximo hacia 1985 y permaneció prácticamente invariable por cerca de 25 años. Con base en las proyecciones poblacionales se ha iniciado un proceso de desconcentración que, no obstante, continuará acompañado de un crecimiento en la primacía poblacional bogotana. Esto quiere decir que por debajo de las once primeras ciudades en la jerarquía poblacional urbana deben estar ocurriendo crecimientos poblacionales urbanos de alguna envergadura que contribuirán a la desconcentración, lo que se podría aducir como un auge de las ciudades intermedias. 


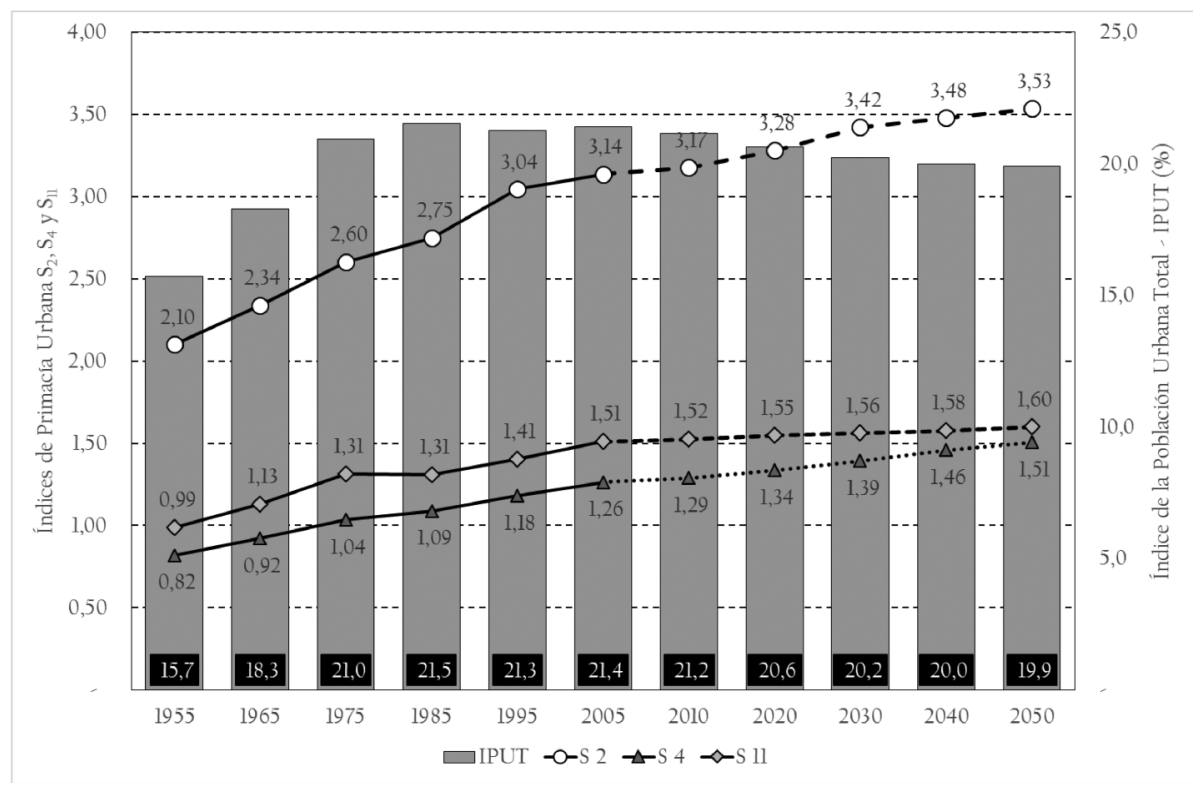

Figura 1. La primacía poblacional urbana de Bogotá: el pasado y el futuro probable. Fuente: cálculos con base en estadísticas censales del DANE hasta el 2005 y proyecciones al 2020, y proyecciones de la Misión de Ciudades — DNP — desde el 2021.

Este auge es improbable al menos en el sistema urbano colombiano por varias razones como lo es la ausencia de una intervención estatal de tal envergadura como para reordenar los procesos de ocupación del territorio; esto, para producir la bifurcación que modifique la trayectoria dependiente de la urbanización de la población. Hace 25 años se pensó que tal bifurcación ocurriría por causa del avance de la globalización y de la exposición del aparato productivo a la competencia internacional. Por el contrario, se ha puesto de manifiesto el interés de los agentes del mercado en concentrar selectivamente sus inversiones mercantiles en zonas con mercados densos. No menos importante, se ha acentuado la crisis perenne de los sistemas agropastoriles que también embarga a algunos agroindustriales situados lejos de las metrópolis; crisis que ocurre en un contexto de creciente ilegalidad e ilegitimidad de la propiedad del suelo en el campo. 
Quedatansolounavía deexplicación:los avances dela metropolización. En la mayoría de los casos, el fenómeno de la metropolización antecede al de la megalopolización. La consolidación de megalópolis concentradas es una tendencia comandada por Tokio y sus conurbados Chiba y Kanagawa; fenómeno que se consolidó con el relevo de Kioto como capital del Japón y el énfasis modernizante introducido por la dinastía Meiji. Por su parte la megalópolis desconcentrada más emblemática es New York; la cual, aún y como lo señalaba Gottmann (1966) hace medio siglo, continúa extendiendo su área de influencia por la "fachada atlántica" (p. 161) de los Estados Unidos; incidiendo en la vida política de Washington, el frente cultural de la conurbación Boston-Cambridge al igual que el comercio de Connecticut, Filadelfia y Baltimore.

Aunque hacia 1995 se tenían medidas de la creciente interacción de la población de ciertos núcleos metropolitanos, con las jurisdicciones municipales de su entorno inmediato (Jaramillo y Alfonso, 2001; Alfonso, 2010), fueron los resultados del Censo General de 2005 los que confirmaron el avance de la metropolización de la población en Colombia. Soledad municipio metropolizado con Barranquilla y Soacha metropolizado con Bogotá, irrumpen desde entonces dentro de la jerarquía urbana colombiana ocupando los lugares nueve y diez y desplazando a capitales departamentales como Santa Marta y Pereira. De igual forma Bello en el Valle de Aburrá es relevado por Soledad y Soacha, pero a la vez releva a Villavicencio para ubicarse en el puesto trece de la jerarquía urbana colombiana.

El fenómeno metropolitano soledeño es singular en Colombia y en el resto del mundo en urbanización. Hace una década se advertía que la tasa de formación de hogares en Soledad era más elevada que la de Barranquilla y que por lo tanto sería el municipio metropolizado el que absorbería al núcleo metropolitano (Alfonso, 2014). Un rasgo que comparten de manera diáfana Soledad y Soacha es que la creciente interacción con los núcleos metropolitanos obedece, en especial, a su papel como amortiguadores de los desaciertos y omisiones de las políticas urbanas en estos últimos; especialmente, de las políticas de suelo urbano del conjunto de las zonas metropolitanas. Estos tres municipios metropolizados han adquirido mayor relevancia que cualquier ciudad que se pueda denominar intermedia en la jerarquía urbana colombiana. 
Con los análisis realizados en los últimos censos, complementados con actualizaciones posteriores basadas en estudios indirectos (Alfonso, 2014) y en consultas y observaciones sobre el terreno, la jerarquía del sistema de ciudades estaría comandada por nueve zonas metropolitanas. Los análisis originales establecieron el saldo migratorio entre cada jurisdicción (núcleos metropolitanos con cada municipio metropolizado) para luego construir una visión de conjunto a partir de un índice de metropolización. Este criterio estadístico hace que las jurisdicciones municipales que conforman las zonas metropolitanas consideradas aquí (tabla 3), difieran notablemente tanto de las consideradas por la autoridad estadística -DANE - en sus diferentes operativos como las que hacen parte de las áreas metropolitanas legalmente constituidas. En 1995, las zonas metropolitanas acogían al 58,5\% de la población urbana colombiana y una década después lo hacían con el 58,6 \%; una participación considerable, aunque ralentizada que amerita una revisión detallada de cada una de ellas.

Tabla 3. Las zonas metropolitanas y las proyecciones poblacionales, Colombia 2020

\begin{tabular}{|c|c|c|c|c|}
\hline \multirow{2}{*}{$\begin{array}{l}\text { Núcleos } \\
\text { metropolitanos }\end{array}$} & \multirow[t]{2}{*}{ Municipios metropolizados } & \multicolumn{3}{|l|}{ Población 2020} \\
\hline & & $\begin{array}{l}\text { Núcleo } \\
\text { metropolitano }\end{array}$ & $\begin{array}{l}\text { Municipios } \\
\text { metropolizados }\end{array}$ & Total \\
\hline Bogotá & $\begin{array}{l}\text { Bojacá, Cajicá, Cota, } \\
\text { Chía, El Rosal, Facatativá, } \\
\text { Funza, Fusagasugá, } \\
\text { Gachancipá, La Calera, } \\
\text { Madrid, Mosquera, Sibaté, } \\
\text { Soacha, Sopó, Subachoque, } \\
\text { Tabio, Tenjo, Tocancipá, } \\
\text { Zipaquirá, Silvania, } \\
\text { Choachí, Cogua, Suesca }\end{array}$ & $8^{\prime} 372153$ & $1^{\prime} 559558$ & $9^{\prime} 931711$ \\
\hline $\begin{array}{l}\text { Valle de } \\
\text { Aburrá }\end{array}$ & $\begin{array}{l}\text { Barbosa, Bello, Caldas, } \\
\text { Copacabana, Envigado, } \\
\text { Girardota, Itagüí, La Ceja, } \\
\text { La Estrella, Marinilla, } \\
\text { Rionegro, Sabaneta, } \\
\text { Guarne, El Retiro }\end{array}$ & $2^{\prime} 554188$ & $1^{\prime} 503444$ & $4^{\prime} 057632$ \\
\hline Cali & $\begin{array}{l}\text { Candelaria, Jamundí, } \\
\text { Palmira, Yumbo }\end{array}$ & $2^{\prime} 470832$ & 495700 & $2^{\prime} 966532$ \\
\hline
\end{tabular}




\begin{tabular}{lllll}
\hline Barranquilla & $\begin{array}{l}\text { Galapa, Malambo, Puerto } \\
\text { Colombia, Soledad }\end{array}$ & 1'236089 & 895588 & 2'131677 \\
\hline Bucaramanga & $\begin{array}{l}\text { Floridablanca, Girón, } \\
\text { Piedecuesta, Lebrija }\end{array}$ & 523892 & 612789 & 1 1'136681 \\
\hline Cúcuta & $\begin{array}{l}\text { El Zulia, Los Patios, San } \\
\text { Cayetano, Villa del Rosario }\end{array}$ & 668959 & 198777 & 867736 \\
\hline Pereira & $\begin{array}{l}\text { Dosquebradas, La Virginia, } \\
\text { Santa Rosa de Cabal, } \\
\text { Cartago }\end{array}$ & 409105 & 432178 & 841283 \\
\hline Manizales & $\begin{array}{l}\text { Chinchiná, Neira, } \\
\text { Villamaría, Palestina }\end{array}$ & 377236 & 126727 & 503963 \\
\hline Armenia & $\begin{array}{l}\text { Calarcá, La Tebaida, } \\
\text { Circasia, Montenegro }\end{array}$ & 296798 & 171801 & 468599 \\
\hline
\end{tabular}

Fuente: cálculos con base en estadísticas censales del DANE hasta el 2005 y proyecciones al 2020, y proyecciones de la Misión de Ciudades —DNP— desde el 2021.

La consideración de las nueve zonas metropolitanas tiene la propiedad de hacer contraer la primacía de la capital a todos los niveles. El análisis retrospectivo de la figura $3^{1}$ sugiere una tendencia con una pendiente más suavizada que la de la figura 2, sin embargo el índice urbano total metropolitano -IUTM - también es superior en todos los casos. Estas tres constataciones son las que, en principio, conducen a la formulación de la hipótesis opuesta a la del auge de las ciudades intermedias; es decir que Colombia es un país de regiones metropolitanas. Por esta razón, no todos los flujos financieros y de bienes y servicios gravitan sobre la zona metropolitana de Bogotá. La existencia de estas zonas ha permitido también que la población residente en el territorio colombiano se estabilice, habiendo comenzado a desvanecerse su volatilidad migratoria hacia comienzos o mediados de la década de los 80 .

\footnotetext{
${ }^{1}$ Para hacer comparable el ejercicio con el anterior, en particular para el cálculo del indicador $S_{11^{\prime}}$ se incluyó a Cartagena e Ibagué como pertenecientes a este régimen.
} 


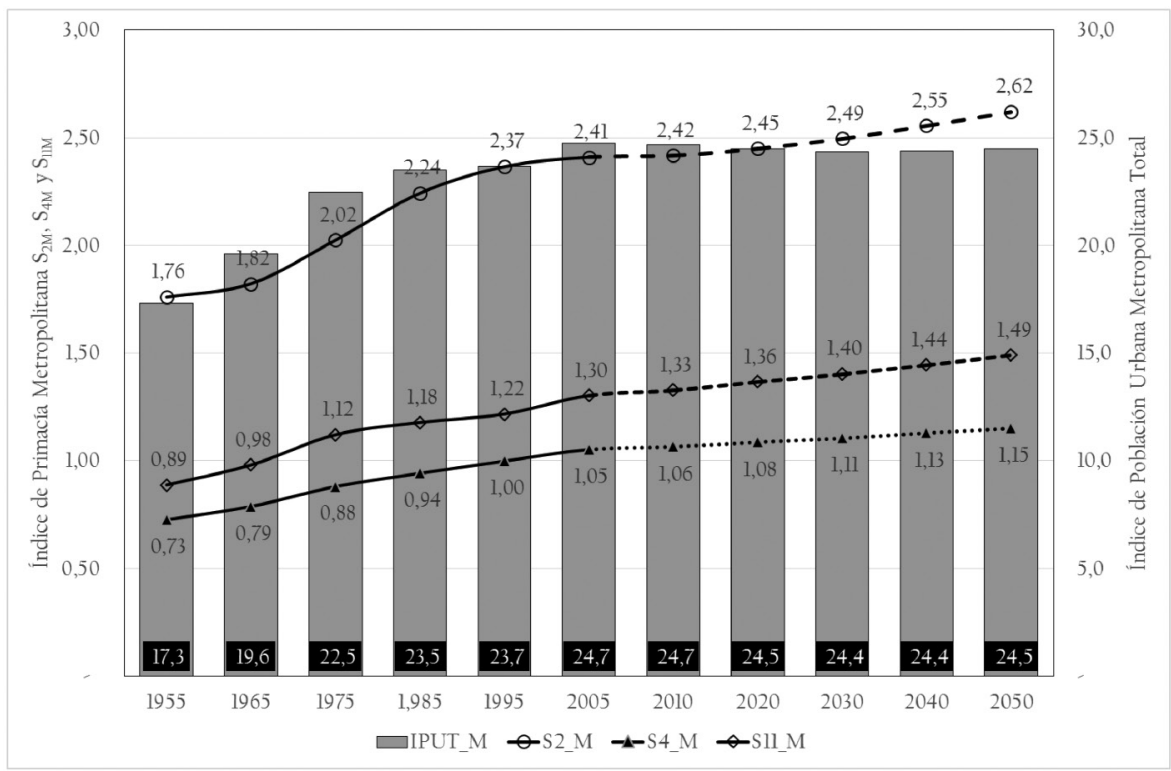

Figura 2. La primacía poblacional urbana de la zona metropolitana de Bogotá: el pasado y el futuro probable.

Fuente: cálculos con base en estadísticas censales del DANE hasta el 2005 y proyecciones al 2020, y proyecciones de la Misión de Ciudades —DNP— desde el 2021.

Analizado en conjunto, el poblamiento de las zonas metropolitanas trae noticias diferentes a las que se han presentado hasta ahora. La primera es que hay una leve, pero persistente, aceleración del poblamiento urbano en la zona metropolitana de Bogotá (tabla 4) si se compara con el ritmo del núcleo urbano presentado en la tabla 1; fenómeno que contrasta con la notable parsimonia del poblamiento del resto de zonas metropolitanas y con la reticencia del Estado a facilitar la organización de un área metropolitana con soporte jurídico y menos aún con autonomía política, ausencia de gobierno metropolitano a la que se ha denominado como la utopía metropolitana (Alfonso et al., 2014). La segunda es que la zona metropolitana del Valle de Aburrá, con su núcleo Medellín a la cabeza, alcanzó los tres millones de habitantes en el 2000 y llegará a los cuatro millones en 2019. Este dinamismo está alimentado por lo que ocurre en Bello, hecho sintomático de la densificación de una zona metropolitana que hoy presenta signos de abandono de su tradicional encapsulamiento al decir de la proliferación de la suburbanización residencial en Rionegro, Guarne y El Retiro; jurisdicciones que también acogen dotaciones de escala internacional como el aeropuerto José María Córdova y establecimientos hospitalarios especializados. En 2054, la zona metropolitana alcanzará 
los cinco millones de habitantes y sobre ella continuarán gravitando los principales flujos económicos y poblacionales del noroccidente del país.

El poblamiento de la zona metropolitana de Cali también se acelera y en 2021 habrá alcanzado los tres millones de habitantes, umbral que alcanzará Barranquilla en 2084. En el oriente colombiano, la zona metropolitana de Bucaramanga alcanzó el millón de habitantes en 2007; mientras que la porción colombiana de la zona metropolitana de Cúcuta, lo tendrá en 2038. Las restricciones geográficas que la meseta le impone al crecimiento poblacional bumangués harán que este se desborde hacia Lebrija, en cuya jurisdicción opera el aeropuerto Palonegro. Por su parte la inestabilidad política y cambiaria colombo-venezolana es una de las limitaciones estructurales que enfrenta la expansión cucuteña. El Eje Cafetero tiene tres nodos metropolitanos que sostienen interacciones con algunas jurisdicciones municipales circunvecinas, pero las de mayor trascendencia son las que ocurren entre ellos mismos. Esta zona metropolitana alcanzó el millón de habitantes en 1980, pero difícilmente alcanzará los dos millones. Las pronunciadas oscilaciones del mercado mundial cafetero han forzado a la transformación productiva de la zona que ha colocado cierto énfasis en el turismo consumidor del Paisaje Cultural Cafetero y más recientemente en la educación superior como ejes de tal transformación.

La segunda aproximación sugerida, los aportes al crecimiento poblacional urbano, se construyeron con base en los resultados de los censos de población hasta 2005 y de allí en adelante con las proyecciones oficiales del gobierno colombiano. Los resultados de la tabla 4 se construyeron con la metodología sugerida por la CGLU y en ellos se puede constatar que después de 1975 los aportes de las metrópolis se han reducido casi en un $10 \%$; fenómeno que también embarga a las ciudades intermedias de mayor tamaño, aunque con menor intensidad. En contraposición, los aportes del resto de ciudades intermedias se moderarán llegando inclusive a decrecer levemente. Los aportes de las ciudades pequeñas que también se han venido contrayendo experimentarán, a la luz de las proyecciones, un inusitado crecimiento que de llegar a ocurrir constituiría en efecto un auténtico 'boom'. Es decir que el sistema urbano de Colombia estaría experimentando en estos momentos una bifurcación tal que la sacaría de su trayectoria dependiente para relocalizar el crecimiento urbano en las ciudades pequeñas y no necesariamente en las metrópolis y en las ciudades intermedias. 
Tabla 4. Los aportes de las ciudades al crecimiento poblacional urbano según la clasificación de CGLU en 2015: retrospectiva y proyecciones

\begin{tabular}{|c|c|c|c|c|c|c|c|c|}
\hline $\begin{array}{l}\text { Categoría } \\
\text { CGLU }\end{array}$ & $\begin{array}{l}\text { Tamaño en } \\
2005\end{array}$ & $1955-65$ & $1965-75$ & $1975-85$ & 1985-95 & 1995-05 & $2005-15^{*}$ & $2015-25^{*}$ \\
\hline Metrópolis & $\begin{array}{l}\text { Más de } \\
\text { 1'000000 }\end{array}$ & 41,8 & 47,6 & 38,8 & 33,6 & 38,1 & 29,1 & 26,3 \\
\hline \multirow{4}{*}{ 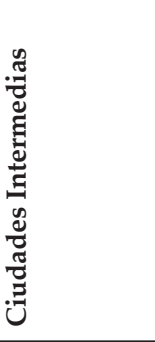 } & $\begin{array}{l}\text { Entre } 500000 \\
\text { y } 1^{\prime} 000000\end{array}$ & 6,1 & 6,3 & 6,0 & 6,9 & 4,0 & 3,6 & 3,1 \\
\hline & $\begin{array}{l}\text { Entre } 300000 \\
\text { y } 500000\end{array}$ & 8,9 & 7,7 & 12,3 & 12,2 & 15,5 & 12,5 & 12,9 \\
\hline & $\begin{array}{l}\text { Entre } 100000 \\
\text { y } 300000\end{array}$ & 11,7 & 12,7 & 15,5 & 13,6 & 14,2 & 13,7 & 14,0 \\
\hline & $\begin{array}{l}\text { Entre } 50000 \text { y } \\
100.00\end{array}$ & 7,4 & 6,8 & 8,3 & 10,1 & 11,0 & 10,7 & 10,8 \\
\hline $\begin{array}{l}\text { Ciudades } \\
\text { Pequeñas }\end{array}$ & $\begin{array}{l}\text { Menos de } \\
50000\end{array}$ & 24,1 & 18,9 & 19,0 & 23,6 & 17,3 & 30,4 & 32,8 \\
\hline Total & & 100,0 & 100,0 & 100,0 & 100,0 & 100,0 & 100,0 & 100,0 \\
\hline
\end{tabular}

Fuente: cálculos con base en estadísticas censales del DANE hasta el 2005 y proyecciones al 2020, y proyecciones de la Misión de Ciudades —DNP_ desde el 2021.

Las agrupaciones de la tabla 3 se han colocado como pívot en 2005 para realizar el análisis retrospectivo y prospectivo de la tabla 5. La cara de la metropolización se ha revelado, desde mediados de los 80, como el fenómeno dominante sobre el que se erige la jerarquía urbana. Desde entonces, los aportes de los núcleos metropolitanos al crecimiento poblacional urbano se contraen para dar paso al crecimiento incremental de los municipios metropolizados en proximidad. Las proyecciones poblacionales sugieren una improbable bifurcación por el abandono del sistema urbano de su trayectoria dependiente, representada en una veloz e inédita contracción de los aportes de las zonas metropolitanas al crecimiento poblacional urbano. Las jurisdicciones municipales de crecimiento poblacional robusto han experimentado un crecimiento relativamente estable, acogiendo a algo más de la tercera parte de este crecimiento. El crecimiento en las jurisdicciones urbanas endebles es de menor calado, aunque de signo positivo; mientras que en las rurales endebles el decrecimiento poblacional, al igual que en las jurisdicciones frágiles, se ha hecho evidente desde 1995. 
Tabla 5. Los aportes de las ciudades al crecimiento poblacional urbano según una nueva tipología en 2005: retrospectiva y proyecciones

\begin{tabular}{llllllll}
\hline Tipología & $\mathbf{1 9 5 5 - 6 5}$ & $\mathbf{1 9 6 5 - 7 5}$ & $\mathbf{1 9 7 5 - 8 5}$ & $\mathbf{1 9 8 5 - 9 5}$ & $\mathbf{1 9 9 5 - 0 5}$ & $\mathbf{2 0 0 5 - 1 5 ^ { * }}$ & $\mathbf{2 0 1 5 - 2 5 ^ { * }}$ \\
\hline $\begin{array}{l}\text { Zonas } \\
\text { metropolitanas }\end{array}$ & 60,5 & $\mathbf{6 4 , 5}$ & $\mathbf{6 0 , 9}$ & 56,6 & 62,5 & 50,3 & 48,3 \\
\hline $\begin{array}{l}\text { Núcleo } \\
\text { metropolitano }\end{array}$ & 50,4 & 53,6 & 44,2 & 40,9 & 40,6 & 31,6 & 28,3 \\
\hline $\begin{array}{l}\text { Municipios } \\
\text { metropolizados } \\
\text { próximos }\end{array}$ & 10,0 & 10,9 & 16,7 & 15,7 & 21,7 & 18,5 & 19,8 \\
\hline $\begin{array}{l}\text { Municipios } \\
\text { metropolizados } \\
\text { lejanos }\end{array}$ & 0,1 & 0,0 & 0,0 & 0,1 & 0,1 & 0,1 & 0,2 \\
\hline Resto del país & 39,5 & 35,5 & 39,1 & 43,4 & 37,5 & 49,7 & 51,7 \\
\hline Robusto & 31,8 & 29,8 & 33,4 & 34,4 & 37,8 & 42,2 & 43,5 \\
\hline $\begin{array}{l}\text { Urbano } \\
\text { endeble }\end{array}$ & 3,8 & 3,6 & 3,9 & 5,0 & 5,1 & 7,0 & 7,6 \\
\hline Rural endeble & 3,6 & 2,1 & 1,6 & 2,8 & $-4,1$ & 0,3 & 0,3 \\
\hline Frágil & 0,4 & 0,1 & 0,2 & 1,1 & $-1,3$ & 0,2 & 0,2 \\
\hline Total & 100,0 & 100,0 & 100,0 & 100,0 & 100,0 & 100,0 & 100,0 \\
\hline
\end{tabular}

Fuente: cálculos con base en estadísticas censales del DANE, proyecciones del DANE y del DNP; $\left(^{*}\right)$ proyecciones.

La atribución de la potencia funcional de las ciudades intermedias también debe ser verificada. Ella parece depender, en buena medida, de los servicios de logística que prestan debido a su localización estratégica y que en el caso colombiano le otorga ciertas ventajas por la movilización de carga importada y exportada en sus puertos del Atlántico como Barranquilla — que es núcleo metropolitano- y Cartagena — que no lo es- y en el Pacífico como Buenaventura — que es la jurisdicción municipal que comanda el desplazamiento forzado- Ese potencial logístico ha existido desde antaño y por lo tanto no podría atribuirse como determinante de algún auge repentino de estas ciudades.

El ISTF recoge dos dimensiones, la económica y la política. En la primera se consideran los flujos de carga entre jurisdicciones tanto de origen como de destino y por tipo de bien (agroalimentos, bienes agroindustriales, resto de bienes agrícolas, alimentos de origen animal, ganado y aves, bienes industriales, maquinaria y equipo y el resto de bienes no clasificados), así como el número de jurisdicciones con las que se sostienen relaciones 
mercantiles. En la dimensión política se han considerado las entidades estatales de diferente orden y su presencia en el territorio, asignándosele una ponderación de acuerdo con su escala y complejidad, así: entidades del orden nacional, $60 \%$; regionales, $20 \%$; departamentales, $15 \%$ y finalmente municipales, $5 \%$. Con el fin de captar las diferencias de grado, o distancias de cada variable entre jurisdicciones, se realiza el procedimiento de estandarización de acuerdo con la ecuación 8; obteniéndose con ello una diferencia ponderada en la que la mejor situación se aproxima a la unidad y la peor a cero, distribuyéndose en este rango el resto de medidas:

$$
x_{e}=\frac{x_{\text {observado }}-x_{\text {minimo }}}{x_{\text {máximo }}-x_{\text {minimo }}}
$$

Se emplean los valores mínimos y máximos endógenos de cada variable, a saber, los efectivamente observados. El valor mínimo en todos los casos es cero. Los resultados de la tabla 6 se desprenden, en principio, de que hay cuatro metrópolis con más de un millón de habitantes -Bogotá, Medellín, Cali y Barranquilla- que además de detentar los valores más elevados del ISTF son también núcleos metropolitanos. El primer grupo de las ciudades intermedias lo componen otros dos núcleos metropolitanos: Cúcuta y Bucaramanga, y Cartagena. Santa Marta, Villavicencio e Ibagué son los municipios no metropolitanos que hacen parte del tercer grupo. Es decir que habría cuatro ciudades intermedias entre las primeras 16 rankeadas por el ISTF, aunque todas lejanas del primer grupo.

Tabla 6. El índice sintético de tamaño funcional, según la clasificación de CGLU en 2015: retrospectiva y proyecciones

\begin{tabular}{|c|c|c|c|c|}
\hline \multirow[t]{2}{*}{ Categoría CGLU } & \multirow[t]{2}{*}{ Tamaño en 2005} & \multicolumn{3}{|l|}{ ISTF } \\
\hline & & Promedio & Máximo & Mínimo \\
\hline Metrópolis & Más de 1’000000 & 0,49 & 1,00 & 0,31 \\
\hline \multirow{4}{*}{ 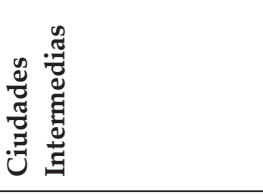 } & Entre 500000 y 1'000000 & 0,20 & 0,26 & 0,15 \\
\hline & Entre 300000 y 500000 & 0,08 & 0,15 & 0,01 \\
\hline & Entre 100000 y 300000 & 0,06 & 0,16 & 0,01 \\
\hline & Entre 50000 y 100000 & 0,04 & 0,10 & 0,00 \\
\hline Ciudades pequeñas & Menos de 50000 & 0,01 & 0,06 & 0,00 \\
\hline Total & & 0,01 & 1,00 & 0,00 \\
\hline
\end{tabular}

Fuente: cálculos con base en estadísticas censales del DANE, del Departamento Administrativo de la Función Pública y del Ministerio del Transporte. 
Estos resultados difieren cuando se presentan con arreglo a la metodología propuesta en la que se reafirma el fenómeno de la metropolización como fase dominante del proceso de urbanización de la población colombiana. En promedio, el ISTF es superior en las zonas metropolitanas que en el resto del país (tabla 7). La funcionalidad de Bogotá cuyo índice es el más elevado, obedece tanto a la densidad de su mercado como a la concentración de poderes en su jurisdicción en la que se localiza la mayor proporción del empleo público de soporte del aparato estatal. La distancia funcional de los núcleos metropolitanos con los municipios metropolizados de su área de influencia inmediata es considerable; de manera que, aunque es la fase dominante de la urbanización, el proceso de metropolización se encuentra aún en ciernes restando un largo camino por recorrer en materia de desconcentración funcional. En las jurisdicciones de crecimiento robusto sobresalen Cartagena y Buenaventura, dos ciudades puerto cuya funcionalidad para el mercado colombiano es crucial; pero la gobernabilidad de ellas es muy baja principalmente en Buenaventura asolada por la violencia homicida, lo que la ha llevado a erigirse como la principal protagonista del desplazamiento forzado.

Tabla 7. Los aportes de las ciudades al crecimiento poblacional urbano según una nueva tipología en 2005: retrospectiva y proyecciones

\begin{tabular}{llll}
\hline \multirow{2}{*}{ Tipología } & ISTF & & \\
\cline { 2 - 4 } & Promedio & Máximo & Mínimo \\
\hline Zonas metropolitanas & 0,10 & 1,00 & 0,00 \\
\hline Núcleo metropolitano & 0,28 & 1,00 & 0,07 \\
\hline Municipios metropolizados próximos & 0,02 & 0,10 & 0,00 \\
\hline Municipios metropolizados lejanos & 0,01 & 0,02 & 0,00 \\
\hline Resto del País & 0,01 & 0,26 & 0,00 \\
\hline Robusto & 0,01 & 0,26 & 0,00 \\
\hline Urbano endeble & 0,01 & 0,08 & 0,00 \\
\hline Rural endeble & 0,00 & 0,03 & 0,00 \\
\hline Frágil & 0,00 & 0,01 & 0,00 \\
\hline Total & 0,01 & 1,00 & 0,00 \\
\hline
\end{tabular}

Fuente: cálculos con base en estadísticas censales del DANE, del Departamento Administrativo de la Función Pública y del Ministerio del Transporte. 
El análisis comparativo de los aportes al crecimiento poblacional urbano y de la funcionalidad presentado en las tablas 4 a 6 se ha hecho para poner de manifiesto la debilidad que representa para este tipo de análisis emplear rangos ad hoc de población; los cuales, además de ser estáticos, desnaturalizan el carácter de algunos centros urbanos que están involucrados decididamente en la fase de metropolización.

\section{Reflexiones finales}

La urbanización de la población colombiana se ha afianzado hasta ingresar desde mediados de los 80 en una fase de metropolización que, tres décadas después, aún no alcanza su cúspide; es decir que los procesos de suburbanización residencial y de desconcentración funcional son apenas incipientes. Desde la perspectiva teórica empleada en esta reflexión, es impensable que cuando esto ocurre simultáneamente se lleve a cabo una desconcentración en ciudades intermedias localizadas por fuera de los ámbitos metropolitanos capaz de modificar sustancialmente la estructura del sistema urbano colombiano. Motivo de preocupación lo constituyen las proyecciones poblacionales oficiales que anuncian que en efecto está ocurriendo tal modificación sustancial de la estructura del sistema urbano y que será un fenómeno duradero por lo menos hasta el 2050. Estas proyecciones no son más que un sustituto poco fiable del Censo de Población que el nivel central de gobierno, a quien compete hacerlo, no ha realizado: el XVIII Censo Nacional de Población y VII de Vivienda estaba previsto para el 2016 (DANE, 2014). Depositar la confianza en esto es un error al no existir evidencias de las razones por las cuales estaría ocurriendo esta bifurcación. El diseño y adopción de estrategias de re-censamiento de la población como las que efectúa periódicamente el INSÉE (2017), son cada vez más urgentes en Colombia.

Un fenómeno de tal naturaleza, bifurcación, puede ocurrir como resultado de una modificación institucional de trascendencia como ocurrió con el sistema de empadronamiento en China, de una agresiva política de fomento a la desconcentración de la producción de valor agregado industrial que no ha ocurrido o por causa de una modificación del modelo territorial de Estado que dé lugar a una desconcentración de funciones en otros lugares del territorio que, siendo totalmente deseable, tampoco se vislumbra que ocurra ante el arraigado sistema centralista colombiano. La desconcentración poblacional y funcional del sistema urbano colombiano es un fenómeno deseable por razones tales como la necesidad de la 
distribución de la producción de riqueza en otros lugares en los albores de la paz territorial, así como por la ingobernabilidad metropolitana; no obstante, no hay evidencias de cambio convincentes para corroborar que ello esté ocurriendo.

\section{Referencias bibliográficas}

Alfonso, Ó. (2010). Profundización de las relaciones de metropolización de Bogotá con la Sabana. En S. Jaramillo (Ed.), Bogotá en el cambio de siglo: promesas y realidades. Quito, Ecuador: OLACCHI.

Alfonso, Ó. (2014). Los desequilibrios territoriales en Colombia: estudios sobre el sistema de ciudades y el polimetropolitanismo. Bogotá, Colombia: Universidad Externado de Colombia.

Alfonso, Ó. et al. (2014). La utopía metropolitana I. Cuatro estudios sobre la metropolización planetaria y los obstáculos para su reconocimiento político. Bogotá, Colombia: Universidad Externado de Colombia.

Barro, R.J. and Sala-i-Martín, X. (1991). Convergence Across States and Regions. Brookings Papers on Economic Activity, 1, 107-182.

Barro, R.J. and Sala-i-Martín, X. (1992). Convergence. Journal of Political Economy, 100 (2), 223-251.

Beál, V. et al. (2017). Villes en décroissance. Métropolitiques. Recuperado de http://www.metropolitiques.eu/Villes-en-decroissance.html.

Bellet, C. y Llop, J.M. (2004). Miradas a otros espacios urbanos: las ciudades intermedias. Scripta Nova, Revista Electrónica de Geografía y Ciencias Sociales, VIII (165).

Cauchi-Duval, N., Cornuau, F. and Rudolph, M. (2017). Shrinking Cities in France: The Cumulative Effects of Decline. Métropolitiques. Recuperado de http://www.metropolitiques.eu/Shrinking-Cities-in-France-The.html.

CEPAL. (1998). Ciudades intermedias de América Latina y el Caribe: propuestas para la gestión urbana. Santiago de Chile, Chile: CEPAL.

CGLU. (2015). Documento marco del CGLU para ciudades intermedias: planificación y gestión del desarrollo urbano sostenible en ciudades intermedias. Recuperado de https://www.uclg.org/sites/default/files/cglu_documento_marco_ci_0.pdf.

Chasco, P. (2000). Modelos de gravitación comercial: una aplicación al anuario comercial de España. Madrid, España: Universidad Autónoma de Madrid.

Coulombe, S. et Lee, F.C. (1998). Évolution à long terme de la convergence régionale au Canada. L'Actualité Économique. Revue d'Analyse Économique, 74 (1), 5-27.

Cuervo, L.M. (2004). Desarrollo económico y primacía urbana en América Latina: una visión histórico-comparativa. En A. Torres (Comp.), El rostro urbano de América Latina. Buenos Aires, Argentina: CLACSO, ASDI.

Dall'Erba, S. et Le Gallo, J. (2005). Dynamique du processus de convergence régionale en Europe. Région et Développement, 21, 119-139.

DANE. (2014). Memoria del taller de experiencias de los censos de población y vivienda de la ronda 2010. Bogotá, Colombia: Departamento Administrativo Nacional de Estadística.

Dormois, R. and Fol, S. (2017). Urban Shrinkage in France: An Invisible Issue? Métropolitiques. Recuperado de http://www.metropolitiques.eu/Urban-Shrinkage-in-France-An.html.

Fresneda, Ó., Moreno, P.I. y Alfonso, Ó. (1998). La red urbana colombiana: una visión a partir del tamaño funcional y la especialización económica de las ciudades. En L. Sarmiento (Ed.), Municipios y regiones de Colombia: una mirada desde la sociedad civil. Bogotá, Colombia: Fundación Social. 
Fujita, M., Krugman, P. y Venables, A.J. (2000). Economía espacial: las ciudades, las regiones y el comercio internacional. Barcelona, España: Editorial Ariel.

Gottmann, J. (1966). América. Barcelona, España: Editorial Labor.

Hackwort, J. (2017). Urban Decline is Not Natural. Métropolitiques. http://www.metropolitiques. eu/Urban-Decline-Is-Not-Natural.html.

Hoenigsberg, H.F. (1977). La crisis poblacional. Bogotá, Colombia: Universidad de los Andes, Editorial Presencia.

INSÉE. (2017). Les résultats des recensements de la population. Recuperado de https://www. insee.fr/fr/information/2008354.

Isard, W. (1960). Métodos de análisis regional: una introducción a la ciencia regional. Barcelona, España: Editorial Ariel.

Jaramillo, S. y Alfonso, Ó. (2001). Un análisis de las relaciones de metropolización a partir de los movimientos migratorios. Ciudad y región en Colombia: nueve ensayos de análisis socioeconómico y espacial. Bogotá, Colombia: Universidad Externado de Colombia.

Lefèvre, Ch. (2014). Gobernar las metrópolis o el gobierno de las metrópolis. En Ó. Alfonso et al. La utopía metropolitana I. Cuatro estudios sobre la metropolización planetaria y los obstáculos para su reconocimiento político. Bogotá, Colombia: Universidad Externado de Colombia.

Lincoln Institute of Land Policy. (2017). Adaptación de Instrumentos de Planeamiento Territorial para Pequeñas Ciudades. Recuperado de https://www.lincolninst.edu/sites/default/files/ sources/courses/2017-convocatoria-adapatacion-instrumentos-pequenas-ciudades_0. pdf.

Mahoney, J. (2000). Path Dependence in Historical Sociology. Theory and Society, 29 (4), 507548.

Martínez, P. (2016). Trayectoria de la política de telecomunicaciones sociales: un acercamiento histórico a la exclusión digital en Colombia (tesis de posgrado). Doctorado en Estudios Políticos, Universidad Externado de Colombia, Bogotá.

Pallagst, K. (2008). Shrinking Cities: Planning Challenges from de International Perspective. Ohio, USA: Kent State University.

Piperno, S. et al. (2014). Desarrollo urbano e interdependencia fiscal en el área metropolitana de Turín: una exploración preliminar. En Ó. Alfonso et al. La utopía metropolitana I. Cuatro estudios sobre la metropolización planetaria y los obstáculos para su reconocimiento político. Bogotá, Colombia: Universidad Externado de Colombia.

Prager, J-C. et Thisse, J-F. (2010). Économie géographique du développement. Paris, France: La Découverte.

Roberts, B.H. (2015). Gestionando sistemas de ciudades secundarias. Washington, Estados Unidos: Cities Alliance, Banco Interamericano de Desarrollo.

Semana. (2014). El "boom" de las ciudades intermedias. Recuperado de http://www.semana. $\mathrm{com} /$ nacion/articulo/las-ciudades-medianas-de-colombia-viven-un-momento-deauge/382710-3.

Terraza, H., Rubio, D. y Vera, F. (2016). De ciudades emergentes a ciudades sostenibles: comprendiendo y proyectando las metrópolis del siglo XXI. Santiago de Chile, Chile: Banco Interamericano de Desarrollo, ARQ Ediciones.

Torres, P. y Caicedo, C. (2015). Las ciudades intermedias con mayor potencial en Colombia: un sistema de identificación. Santiago de Chile, Chile: Banco Interamericano de Desarrollo.

Vernon, R. (1973). Soberanía en peligro: la difusión multinacional de las empresas de Estados Unidos. Ciudad de México, México: Fondo de Cultura Económica.

Zhuoyong, Ch. (2008). Urbanization and Spatial Structure: Evolution of Urban System in China. IDE-JETRO, 439, 1-34. 